\title{
Diacronie
}

Studi di Storia Contemporanea

$\mathrm{N}^{\circ} 34,2 \mid 2018$

Scuola e società in Italia e Spagna tra Ottocento e Novecento

\section{Contraposición de modelos formativos. Valladolid,} 1931-1959

\section{Sofia Rodríguez Serrador}

\section{(2) OpenEdition \\ Journals}

\section{Edición electrónica}

URL: http://journals.openedition.org/diacronie/8419

DOI: $10.4000 /$ diacronie.8419

ISSN: 2038-0925

\section{Editor}

Association culturelle Diacronie

Referencia electrónica

Sofia Rodríguez Serrador, "Contraposición de modelos formativos. Valladolid, 1931-1959 », Diacronie [En línea], N 34, 2 | 2018, documento 8, Puesto en línea el 29 junio 2018, consultado el 01 mayo 2019. URL : http://journals.openedition.org/diacronie/8419; DOI : 10.4000/diacronie.8419 


\section{Diacronie}

Studi di Storia Contemporanea

34, $2 / 2018$

Scuola e società in Italia e Spagna tra Ottocento e Novecento

\section{Contraposición de modelos formativos. Valladolid, 1931-1959}

\section{Sofía RODRÍGUEZ SERRADOR}

Per citare questo articolo:

RODRÍGUEZ SERRADOR, Sofía, «Contraposición de modelos formativos. Valladolid, 1931-1959», Diacronie. Studi di Storia Contemporanea : Scuola e società in Italia e Spagna tra Ottocento e Novecento, 34, 2/2018, 29/06/2018,

URL: <http://www.studistorici.com/2018/06/29/rodríguez-serrador_numero_34/ >

Diacronie Studi di Storia Contemporanea $\rightarrow$ http://www.diacronie.it Rivista storica online. Uscita trimestrale.

redazione.diacronie@hotmail.it

Comitato di direzione: Naor Ben-Yehoyada - João Fábio Bertonha - Christopher Denis-Delacour - Maximiliano Fuentes Codera Anders Granås Kjøstvedt - John Paul Newman - Deborah Paci - Niccolò Pianciola - Spyridon Ploumidis - Wilko Graf Von Hardenberg

Comitato di redazione: Jacopo Bassi - Luca Bufarale - Gianluca Canè - Luca G. Manenti - Fausto Pietrancosta - Alessandro Salvador - Matteo Tomasoni - Luca Zuccolo Creative Commons 3.0. Possono essere riprodotti e modificati a patto di indicare eventuali modifiche dei contenuti, di riconoscere la paternità dell'opera e di condividerla allo stesso modo. La citazione di estratti è comunque sempre autorizzata, nei limiti previsti dalla legge. 


\title{
8/ Contraposición de modelos formativos. Valladolid, 1931- 1959
}

\author{
Sofía RODRÍGUEZ SERRADOR
}

En esta investigación analizamos la educación de las élites y las culturas escolares generadas en los diversos ámbitos docentes de la segunda enseñanza. La educación es uno de los primeros núcleos de socialización, coadyuvando al proceso mediante el cual las personas asumen los valores y conductas aceptados por el sistema sociopolítico existente. El marco temporal elegido conllevó políticas educativas cuya repercusión es patente en el impacto social, cultural y político de la población escolar. Hemos escogido como modelo de análisis la ciudad de Valladolid por ofrecer un entorno educativo privilegiado, teniendo desde el XIX un Instituto Provincial y buen número de destacados colegios pri-vados confesionales destinados a la formación de las clases medias.

\section{Introducción}

En el marco de la historia sociocultural, nuestra investigación pretende comprobar en qué medida las políticas educativas de los diferentes gobiernos vigentes entre 1931-1959 ${ }^{1}$ - cada una con su ideario propio - tuvieron cumplimiento en los centros escolares vallisoletanos dedicados a impartir la segunda enseñanza - en especial el bachillerato universitario -, una formación reglada enfocada a las élites y clases medias². Igualmente, intenta averiguar el impacto social de las

\footnotetext{
${ }^{1}$ Enmarcamos nuestro trabajo en una de las periodizaciones clásicas del primer franquismo. Sobre el debate historiográfico en torno a esta etapa véase: SÁNCHEZ RECIO, Glicerio, «Líneas de investigación y debate historiográfico», in Ayer, 33, 1999, pp. 17-40. Atendiendo a la enseñanza media en relación al franquismo, podríamos igualmente hacer una periodización propia basada en los cambios legislativos, así una primera etapa iniciada con la ley de Bachillerato de 1938 abarcaría hasta la reforma de 1953. Sin embargo, los pilares ideológicos del sistema educativo continuaron, y además en Valladolid hasta los años 60 - con la apertura de nuevos centros escolares -, el escenario educativo se mantiene sin apenas cambios.

${ }^{2}$ En Valladolid la élite socioeconómica solía ocupar también los principales cargos de la política local. Ya antes de la restauración la ciudad está caracterizada por una economía y estructura social centrada en el sector servicios, al que contribuye la presencia de la Universidad, Audiencia, Obispado y la Academia de Caballería. Véase: LAVASTRES, Philippe, Valladolid et ses élites: les illusions d'une capital eréginale (1840-1900), Madrid, Casa Velázquez, 2007.
} 
políticas pedagógicas e interesarnos en la labor socializadora del entorno educativo.

Buscamos comparar los resultados de esta «revolución» educativa con la «contrarreforma» que provoca la guerra civil, y la nueva escuela impuesta por el régimen franquista. En este sentido, Valladolid ofrece un entorno educativo privilegiado, pues además de ser el principal núcleo poblacional del ámbito castellano, desde el siglo XIX cuenta con un Instituto Provincial y buen número de colegios privados y confesionales de gran relieve e imbricación social, cuya tarea docente continúa hasta la actualidad. La ciudad englobaba los principales centros oficiales y privados, que acogían al mayor porcentaje del alumnado de la capital y provincia, centralizando los estudios a través de la Universidad y el Instituto. A este último estarán adscritos los centros privados de la ciudad, en su mayoría confesionales, que servirán de nexo entre la población urbana y la provincial, gracias a su oferta de internados. El modelo de educación-cohabitación es esencial en la conformación del carácter y la ideología de los educandos, pues una convivencia tan intensa, alejada de elementos referenciales diferentes, permite inculcar de manera más profunda ideas y costumbres. Además, en este contexto tienen una mayor relevancia las actividades extraescolares (asistiendo los alumnos a conferencias, veladas musicales, cinematográficas, visitas científicas a industrias locales o excursiones a otras localidades), que fomentan la disciplina y un modelo de uniformidad en el alumnado.

Fundamentalmente, nuestra investigación se centra en cinco centros: los institutos públicos Zorrilla y Núñez de Arce, y los colegios católicos San José (Compañía de Jesús), La Enseñanza (Compañía de María), Nuestra Señora de Lourdes (Hermanos de La Salle). Dos de ellos, La Enseñanza, y el Instituto Núñez de Arce, son centros para la formación femenina. Los centros privados han congregado a lo largo de su historia a la mayoría de la población escolar, siendo también los preferidos por las élites urbanas ${ }^{3}$ para la educación de sus hijos, creando unas estrechas relaciones entre estas instituciones y los poderes civiles y militares, e incluso la Universidad. Diversos motivos pueden llevar a la elección de los centros privados, como unas mejores instalaciones y medios materiales ${ }^{4}$, pero también evitar que sus hijos se mezclen con un alumnado más popular que puede acudir al Instituto y se relacionen con familias más distinguidas. Respecto de los colegios católicos, además de los estudios que marca la ley, impulsan el conocimiento y la práctica de la religión católica, así como de los valores propios de la comunidad religiosa encargada de la educación en cada centro. Transmiten e inculcan a sus alumnos también una identidad colectiva, la satisfacción de esa pertenencia. Las asociaciones de Alumnos, Antiguos Alumnos y Padres del Colegio, que desarrollan todos ellos, perpetúan esa

\footnotetext{
${ }^{3}$ Sobre la definición de élites remitimos a PRO RUIZ, Juan, «Las élites de la España liberal: clases y redes en la definición del espacio social (1808-1931)», in Historia Social, 21, 1995, pp. 47-69.

${ }^{4}$ Así lo demuestra la documentación consultada. Los centros privados destacan por sus mejores instalaciones sanitarias, incorporación temprana de un sistema de calefacción central y completos gabinetes de Física, Química, Botánica o Zoología.
} 
identidad colectiva ${ }^{5}$. A través de las memorias escolares presentadas al rectorado de la Universidad Literaria y al Ministerio ${ }^{6}$, y las revistas editadas en los propios centros ${ }^{7}$, ha sido posible analizar la vida escolar vallisoletana en el transcurrir diario de estas instituciones docentes. El régimen disciplinario, muy estricto al principio, se verá suavizado con los años. Un ejemplo sería La Enseñanza, cuya Orden directora era de clausura, por lo que las alumnas internas seguían el mismo tipo de vida que las religiosas. Durante el curso escolar solamente abandonaban el centro tres días al año, pasando incluso las fiestas de Navidad. Las alumnas vivían en un marco de disciplina vigilada, a través de la distribución del tiempo por los horarios impuestos desde la dirección y en un ambiente que puede tildarse de religiosidad agobiante, que es propio de la época y común a otras fundaciones docentes, aunque en este caso proviene de su influencia ignaciana, afectando incluso a las visitas que podían recibir en el centro - únicamente los domingos y días de fiesta -, pues estas son atendidas en el locutorio o salón de visitas separado de las internas por un verja que pasado un rato era abierta permitiendo salir a la colegiala ${ }^{8}$.

Mientras en los centros confesionales la mayor preocupación es limitar el contacto con el exterior (el colegio San José prohibirá tratar - e intercambiar objetos - con los de fuera, incluso trabajadores y criados de la casa ${ }^{9}$ ) y mantener un orden riguroso en el funcionamiento diario, el objetivo del Instituto Zorrilla es combatir el absentismo escolar. En todas las fundaciones el factor religioso es abrumador, sobre todo en las confesionales, donde las actividades están muy pautadas, incluso el tiempo de ocio, y es determinante la orientación religiosa que cada congregación imprime en las tareas educativas. El cumplimiento de los deberes espirituales será muy estricto. La asistencia a misa y la realización de ejercicios espirituales es preceptiva, incluso en la década de los cincuenta serán de obligado cumplimiento en los institutos de la ciudad, que cuentan con capilla propia. En la planificación docente de estas instituciones será común la preocupación por la formación religiosa, deportiva y práctica de las materias escolares,

\footnotetext{
${ }^{5}$ Este tipo de asociacionismo educativo y familiar responde al modelo de sociabilidad formal precisado por M. Agulhon y coincide igualmente con la visión de P. Solà sobre el asociacionismo. En el entorno educativo podemos encontrar igualmente multitud de ejemplos de sociabilidad informal, pero como bien señala $\mathrm{E}$. Maza el carácter no reglado de estas experiencias dificulta la tarea de estudio debido a su variedad interna y su dispersión documental. MAZA, Elena, Discurrir asociativo en la España contemporánea, (1839-1941), Valladolid, Ediciones Universidad de Valladolid, Instituto Universitario de Historia Simancas, 2017, p. 10.

${ }^{6}$ Con las diferentes configuraciones administrativas que atravesó en el periodo objeto de estudio: Ministerio de Instrucción Pública y Bellas Artes (1900-1937), Ministerio de Instrucción Pública y Sanidad (1937-1939), Comisión del Cultura y Enseñanza de la Junta Técnica del Estado(1936-1938), Ministerio de Educación Nacional (1938-1966).

${ }^{7}$ Hemos atendido a las publicaciones de los colegios Nuestra Señora de Lourdes, San José (Vallisoletana) y La Enseñanza (Lestonnac). Los institutos carecen de ellas durante el marco cronológico fijado.

${ }^{8}$ Centenario: el Colegio de la Compañía de María «Enseñanza» de Valladolid cumple cien años, 1880-1980, Valladolid, Colegio de la Enseñanza, 1980.

${ }^{9}$ Véase FERNÁNDEZ, Luis, Historia del Colegio San José de Valladolid, 1881-1981, Valladolid, Colegio de San José, 1981.
} 
resaltando notablemente los éxitos obtenidos por el alumnado en los exámenes; después de la guerra civil incidirán en su objetivo de formación patriótica.

Estas circunstancias permiten un estudio diacrónico del impacto de las reformas educativas, analizando las pervivencias de la gramática escolar ${ }^{10}$ o de la cultura(s) escolar(es) ${ }^{11}$ de cada centro, las resistencias y acomodaciones al cambio. Mientras que la coexistencia de fundaciones escolares posibilita un estudio sincrónico de la educación estatal, la confesional y las diferencias entre establecimientos masculinos y femeninos.

El entorno educativo es uno de los primeros núcleos de socialización, favoreciendo el proceso por el cual los individuos asumen normas, valores, actitudes y conductas aceptados y practicados por el sistema sociopolítico existente ${ }^{12}$. La socialización inserta a los sujetos en el seno de una sociedad concreta ${ }^{13}$, permitiendo, incluso que la persona desarrolle una determinada identidad social y política. La escuela genera este tipo de socialización de una manera informal y latente, provocando que el individuo se identifique con un determinado sistema ideológico o político a través de los programas de educación cívica, política o histórica ${ }^{14}$. Este enfoque coincide con la idea de Durkheim de que la función fundamental de las instituciones escolares es la imposición de una determinada cultura como auténtica y legítima, así como la inculcación sistemática y continuada de la misma; estas dinámicas generan mecanismos de dominación y de legitimación, pues imponen una determinada cultura o moral de manera incuestionable, presentándola como la correcta $^{15}$. En esta línea, algunas de las aportaciones enunciadas por Bourdieu, Bernstein y Passerson sobre la teoría de la reproducción cultural ${ }^{16}$ siguen vigentes al aplicarlas al análisis de los sistemas educativos $^{17}$. La teoría de la reproducción se refiere al papel de la educación como reproductora de la cultura, la estructura social y la económica a través de estrategias de clase. La educación impone patrones de autoridad y reproduce el orden social propio de la sociedad de

\footnotetext{
${ }^{10}$ La gramática de la escolaridad alude a la disposición de las aulas, la división del tiempo escolar, la división de materias, la graduación por cursos, el currículo y los exámenes. Estas pautas no se cuestionan, por ser estos hábitos la forma correcta de actuar. Véase: TYACK, David, CUBAN, Larry, En busca de una utopía. Un siglo de reformas de las escuelas públicas, México D. F., Fondo de Cultura Económica, 2001.

${ }^{11}$ Recogemos la definición que da A. Viñao: un conjunto de teorías, ideas, principios, normas, pautas, rituales, inercias, hábitos y prácticas (formas de hacer y de pensar, mentalidades y comportamientos) sedimentadas a lo largo del tiempo en forma de tradiciones, regularidades y reglas de juego no puestas en entredicho, y compartidas por sus actores, en el seno de las instituciones educativas. VIÑAO, Antonio, Sistemas educativos, culturas escolares y reformas, Madrid, Morata, 2002, pp. 73-74.

${ }^{12}$ RAMÍREZ JIMÉNEZ, Manuel, «La socialización política en España: una empresa para la democracia», in Sistema, 34, 1980, pp. 91-116.

${ }^{13}$ BADIE, Bertrand, HERMET, Guy, BIRNBAUM, Pierre, BRAND, Philippe, Dictionnaire de la science politique et des institutions politiques, Paris, Armard Colin, 1994, p. 256.

${ }^{14}$ PERCHERON, Annick, La socialisation politique, París, Armand Colin, 1993, p. 32 et seq.

${ }^{15}$ USÁTEGUI, Elisa, «La educación en Durkheim, ¿socialización versus conflicto?», in Revista Complutense de Educación, XIV, 1/2003, pp. 175-194.

${ }^{16}$ GUERRERO, Antonio, Enseñanza y sociedad. El conocimiento sociológico de la educación, Madrid, Síntesis, 2003, p. 205.

${ }_{17}$ Véase: ÁVILA, Mercedes, «Socialización, Educación y reproducción cultural: Bourdieu y Berstein», in Revista Interuniversitaria de Formación del Profesorado, XIX, 1/2005, pp. 159-174.
} 
clases, legitimando las jerarquías sociales a través de las titulaciones. El éxito de esta tarea radica en la sutilidad, pues los mecanismos de dominación no son percibidos, llegando de este modo a contar la escuela con la adhesión de los sectores más desfavorecidos. La acción pedagógica, definida por los grupos dominantes de la sociedad - de la que se benefician -, es un mecanismo de dominación y violencia simbólica, al imponer un arbitrio cultural (el currículo) que favorece los intereses de dichas clases ${ }^{18}$. En resumen, la educación inculca en los educandos los hábitos intelectuales, morales e incluso laborales de la cultura dominante, desempeñando así un rol en la reproducción del orden social establecido.

\section{La realidad educativa vallisoletana: de la acomodación a la Segunda} República a la adaptación en el franquismo

La política educativa republicana - salvo en el segundo bienio - tuvo dos referentes claros, la Institución Libre de Enseñanza y el pensamiento educativo del PSOE, influidos ambos por el ideario de vanguardias educativas del primer tercio del siglo XX. Los principios educativos que representaban estas corrientes quedaron fielmente recogidos en la Constitución. Así el artículo 48 afirmaba la laicidad de la enseñanza en España, y por el artículo 26 «todas las confesiones religiosas serán consideradas como asociaciones sometidas a una ley especial», prohibiendo la enseñanza a las órdenes religiosas a la vez que disolvía la Compañía de Jesús, nacionalizando además sus bienes para fines benéfico-docentes. Estos planteamientos pronto atrajeron la condena de los obispos españoles y de la Iglesia católica, apelando a la doctrina establecida por Pío XI en el Syllabus y por León XIII en la Encíclica Libertas, amparándose además, en la encíclica de Pío XI Divini Illius Magistri, cuyo punto quinto señala que no puede existir una educación completa si esta no es cristiana, mientras que el punto trece manifiesta el derecho inalienable de la Iglesia a la Educación, anterior incluso al derecho del Estado.

En Valladolid, la II República fue acogida con un remarcable entusiasmo, otorgando la ciudad en las elecciones de abril de 1931 el ayuntamiento a la alianza republicano socialista. En estos primeros momentos las instituciones docentes confesionales vivirán con inquietud las noticias de la quema de conventos y otras muestras anticlericales en diversos puntos del país. Temor fundado en los rumores difundidos por la ciudad. Así, nada más proclamarse el nuevo régimen democrático, algunos antiguos alumnos del colegio de San José harán guardias - armados - en el centro, siendo uno de los más asiduos el jonsista José Antonio Girón de Velasco. El colegio de la Enseñanza fue evacuado ante las noticias de un inminente incendio provocado, congregando

\footnotetext{
${ }^{18}$ Véase: GUERRERO SERÓN, Antonio, Manual de sociología de la educación, Madrid, Síntesis, 1996.
} 
multitud de curiosos en el entorno "para ver salir a las monjas»" ${ }^{19}$. En los días próximos el colegio de Lourdes fue evacuado por el mismo motivo.

La nueva normativa republicana romperá el funcionamiento tradicional de estos centros, que finalmente conseguirán afrontar las nuevas exigencias legales sin mayores problemas. En este panorama, un caso aparte protagoniza el colegio San José de la Compañía de Jesús, pues la disolución de la Institución provocará, colateralmente, una represión de su actividad docente, seguida de un exilio voluntario a Curia (Portugal), provocando un choque social profundo, pues el colegio de la Compañía era uno de los más antiguos, habiendo formado a los hijos de la clase media y alta - entre ellos, militares de la Academia de Caballería - de la ciudad durante décadas. Cuando se llevó a cabo la incautación de los bienes de los jesuitas y, con ellos, del colegio de San José, los allí congregados - en defensa de los religiosos - encabezados, de nuevo, por José Antonio Girón, protestarán al grito de «¡Muera la República!, ¡Fuera los ladrones!», realizando una identificación entre la República y el anticlericalismo que saquea a la Iglesia ${ }^{20}$. Tras la incautación del edifico, el rector de la Universidad Torre Ruiz reseñará en su informe que todas las instalaciones que no pudieron llevarse los religiosos habían sido destruidas o inutilizadas «con verdadera saña», desapareciendo incluso los lavabos de los cuartos de alumnos, y quedando una gran cantidad de cristales rotos en el edificio ${ }^{21}$.

Por el contrario, en los centros estatales no se detectan muchos cambios y la segunda enseñanza aquí mejorará con la creación en el curso 1932-1933 del Instituto Nuevo en la ciudad, rebautizado un año después como Instituto Núñez de Arce. La instalación de dicho instituto en las dependencias del antiguo colegio de San José estuvo acompañada de cierta urgencia e incertidumbre, siendo necesaria además una reforma previa a cargo del arquitecto del Ministerio, Eugenio Sánchez Lozano ${ }^{22}$.

Pero sin duda, la mayor polémica vino con la aprobación de la Ley de Confesiones y Congregaciones religiosas el 17 de mayo de 1933. Era el inicio de lo que algunos autores han denominado «el combate más duro de la guerra escolar» ${ }^{23}$. Aprobada esta Ley, el Papa Pío XI dio a conocer la Encíclica Dilectissima nobis, pidiendo a los católicos que se unieran disciplinados en su contra. Los sectores afectados por la Ley comenzaron a organizarse para que la sustitución no fuera efectiva y les afectara lo menos posible. Así, en Valladolid se publicó un manifiesto de la

\footnotetext{
${ }^{19}$ Lestonnac, XIII, 13/1934, Archivo Colegio La Enseñanza, Compañía de María.

${ }^{20}$ BERZAL, Enrique, Cultura religiosa en el Valladolid de la República: de los cantos litúrgicos al fragor de las armas, en Valladolid. Historia de una ciudad. Vol. III. Época contemporánea, Valladolid, Ayuntamiento de Valladolid, 1999, p. 1077.

${ }^{21}$ Archivo de la Universidad de Valladolid (AUVa), Legajo 1542.

${ }^{22}$ El presupuesto de acondicionamiento ascendió a 32.704,75 pesetas. Seguido un mes después de uno de ampliación por 11.439,87 pesetas. Archivo General de la Administración, Fondo Educación, caja 31/4935.

23 NAVARRO, Clotilde, La educación y el nacional-catolicismo, Murcia, Servicio de Publicaciones de la Universidad de Castilla-La Mancha, 1993, p. 21.
} 
Confederación Católica de Padres de Familia por el que se reclamaba «la unión para impedir el laicismo en la enseñanza de todos los padres de familia católicos, para huir de la escuela laica y crear nuevas escuelas católicas y sostener obras postescolares y circumescolares que faciliten la educación cristiana», fundándose un mes después la Mutualidad de Padres de Familia de Valladolid $^{24}$. Semejante a la Sociedad Anónima de Enseñanza Libre, de ámbito nacional, nacía con la voluntad de defender y asegurar la enseñanza cristiana, disponer para sus hijos escuelas, colegios, internados, centros de cultura secundaria y superior y residencias de estudiantes, para atender a la función educativa, fin y motivo de la mutualidad ${ }^{25}$. Asumirá en septiembre de 1933, la gestión de los colegios Jesús y María ${ }^{26}$, La Sagrada Familia ${ }^{27}$ y La Enseñanza. Se mantendrán en funcionamiento casi todos los centros docentes de las congregaciones, ejerciendo muchos de sus educadores, despojados de sus hábitos, e incluso se logra que las fundaciones sigan rigiéndose de acuerdo con el ideario cristiano. La población, organizada en torno a las asociaciones diocesanas y a la Casa Social Católica, consiguió evitar en la ciudad «en la educación de los escolares católicos los valores, actitudes y comportamientos propios de la cultura política laica propugnada por la Constitución» ${ }^{28}$.

Como indicábamos, salvo el colegio de San José, el resto de fundaciones docentes continuaron su labor y en algunos casos aumentó el número de alumnos, como sucedió en el colegio de Lourdes, que absorbió parte del alumnado de los jesuitas. Aunque para seguir en funcionamiento tuvieron que idear nuevas estratagemas. Así, los Hermanos de la Doctrina Cristiana (Nuestra Señora de Lourdes) crean una sociedad mercantil La Instrucción Popular, que gestionará la fundación como empresa explotadora, intercambiándose los religiosos de Valladolid con otra comunidad docente de hermanos lasallianos. En lo relativo a este nuevo profesorado el centro indicará que «la enseñanza oficial, es incompatible con el estudio del colegio de Lourdes. Aquí todos los alumnos pertenecen a la enseñanza libre y obtienen a fin de curso las mejores notas, como prueba de su trabajo y aplicación» ${ }^{29}$.

Después de esta operación de adaptación los colegios continuaron su funcionamiento habitual, prescindiendo de la coeducación y manteniendo su orientación masculina o femenina, según las congregaciones, salvo leves modificaciones, como pudiera ser la desaparición del traje talar en los religiosos; la educación y el comportamiento no variaron notablemente. Mantuvieron las

\footnotetext{
${ }^{24}$ BERZAL, Enrique, Remigio Gandásegui (1905-1937). Un obispo para una España en crisis, Madrid, Biblioteca de Autores Cristianos, 1999, pp. 222-224.

${ }^{25}$ Archivo Histórico Provincial de Valladolid, Gobernación Civil. Legajo 325.

${ }^{26}$ Pertenece a las Carmelitas Vedrunas.

${ }^{27}$ Pertenece a las Hijas de Jesús.

${ }^{28}$ GÓMEZ CARBONERO, Sonsoles, Cultura ciudadana y socialización política en la República. Actitudes y comportamientos de los Vallisoletanos, Alicante, Biblioteca Virtual Miguel de Cervantes, 2002, p. 268.

${ }^{29}$ Diario Regional, 17/10/1934. Además, durante casi todo el mes de octubre se fueron recibiendo visitas de antiguos alumnos del colegio, ofreciendo su ayuda. Memoria escolar. Curso 1933-1934, Archivo Colegio Nuestra Señora de Lourdes (ACNL).
} 
celebraciones propias, e incluso la Semana Santa y la misa continuaron, pero de manera mucho más discreta, únicamente en el interior del recinto. Así el colegio Nuestra Señora de Lourdes introdujo algunos ajustes en lo religioso: se suprimió la Fiesta de la Inmaculada, y la Semana Santa fue celebrada de puertas para dentro, recorriendo los alumnos los patios y el jardín de la casa siguiendo la procesión litúrgica del día.

Sin embargo, las resistencias al cambio serán notables, y dejarán su impacto también en la vida de la ciudad. Un cierto prototipo de esta postura fue el colegio de Huérfanos de Santiago, de la Academia de Caballería, que mantendrá también las clases de religión y la asistencia a misa de manera preceptiva durante el periodo republicano, motivando que dos de sus alumnos denuncien la situación ante las autoridades y, en consecuencia, sean expulsados. La repercusión del incidente hará que el ayuntamiento notifique al Ministerio de Guerra lo sucedido para que tome medidas. Ya en el aniversario de la proclamación de la República, el colegio no había colgado la bandera tricolor de la fachada, desafiando lo establecido en el marco de las actividades conmemorativas, y provocando, según las crónicas, que un sector de la población apedreara las ventanas, defendiéndose los huérfanos con tirachinas ${ }^{30}$. El impacto republicano originará otro problema en el colegio de La Enseñanza, pues también manifestó su resistencia a los ideales republicanos. Así, en enero de 1933 interpretaron una pequeña función en el colegio que exhibía una bandera monárquica, dándose vivas al rey y tratando despectivamente al régimen republicano ${ }^{31}$. A causa de este episodio las religiosas fueron sancionadas con una multa de 10.000 pesetas, amenazadas incluso con el cierre de la fundación y el destierro de la superiora a Guinea Ecuatorial.

Durante la guerra, en la zona nacional los avances educativos republicanos desaparecen inmediatamente al anularse los aspectos progresistas que las reformas del periodo anterior habían introducido en la enseñanza (escuela neutra, coeducación, inspección de la enseñanza primaria, bilingüismo escolar, etc.). El 18 de julio surge una nueva estructura educativa sustentada y configurada por el incondicional apoyo que, desde el primer momento, la Iglesia católica prestó a la sublevación militar.

De la mano de la labor propagandística de la Iglesia, asistimos a la demolición de las bases jurídicas en que se apoyaba la enseñanza republicana. La Ley de Confesiones y Congregaciones Religiosas, que apenas había tenido un cumplimiento real en el periodo de la CEDA, fue derogada en febrero de $1939^{32}$. La Compañía de Jesús quedó restablecida por Decreto del 3 de mayo de 1938. Igualmente las órdenes religiosas recuperaron la dirección de centros educativos. La asignatura

\footnotetext{
${ }^{30}$ Archivo Municipal de Valladolid, Actas del pleno municipal, 09/07/1932.

${ }^{31}$ Archivo Histórico Nacional, Gobernación, Legajo 18-A, exp. 12, Telegramas entre el gobernador civil de Valladolid y el Ministro de Gobernación, 23-26/01/1932. Cit. en GÓMEZ CARBONERO, Sonsoles, op. cit., p. 548.

${ }^{32}$ Alegando que dicha ley partía de una base falsa, la coexistencia en España de una pluralidad de confesiones religiosas, cuando realmente no había más profesión de fe que la fe católica.
} 
de religión pasó a ser obligatoria en todos los cursos del bachillerato. Se establece la purga de las bibliotecas. En los centros educativos solo serán válidos los libros que se atengan «a los santos principios de la religión y de la moral cristiana» ${ }^{33}$.

Tras el golpe de Estado, Valladolid se sumó rápidamente a la sublevación ${ }^{34}$. La operación encabezada en la ciudad por el general Saliquet (designado a tal efecto, junto con el general Miguel Ponte, por Mola) tendrá por resultado la toma de la VII División Orgánica, de la ciudad y de la provincia.

En estos momentos, la actividad docente tuvo que afrontar nuevas limitaciones. Ya no era la guerra escolar sino la contienda civil lo que marcaba su funcionamiento. Los jesuitas consiguieron de la Junta Técnica del Estado, en septiembre de 1936, que la Compañía ocupara el piso alto del antiguo edificio del colegio en Valladolid, y así volvían a abrir sus puertas. La mayoría de los centros tuvieron instalaciones militares y hospitales de sangre, a pesar de hallarse y ser Valladolid ciudad de retaguardia. En La Enseñanza durante la guerra estuvo asentado en el colegio un depósito de armas, ocupando el salón de actos y el parque de juegos. La Casa fue refugio de las hermanas procedentes de la zona republicana, llegando a cien las desplazadas al convento de Valladolid, veintisiete de ellas desde la Casa de Barcelona incendiada en 1937. Mientras que en el colegio de Lourdes fue instalado el Estado Mayor italiano de Flechas Azules y el Hospital de sangre. Los italianos pretendían acaparar cada vez más espacio, hasta el punto que el director recurrió - mediante intermediarios - al mismo Benito Mussolini, que llamó al orden a sus compatriotas. A pesar de esto, los italianos permanecieron en el edificio hasta 1939. Además de la presencia italiana, el colegio acogía - desde noviembre de 1937 - a una colonia de 15 niños, «hijos de los rojos de Madrid», remitidos por el gobierno de Burgos para que fueran atendidos en el centro $^{35}$.

El retorno de los jesuitas provocó que en el curso 1936-1937, el Instituto Núñez de Arce se trasladara al edificio del Instituto Zorrilla, a modo de su sección femenina, quedando bajo la dirección de este último y debiendo compartir equipo directivo e instalaciones. La evolución de la guerra condicionará fuertemente el desarrollo escolar, tras los bombardeos sufridos en la ciudad en 1937, las alumnas solicitarán al director del Instituto Zorrilla la dispensa de las clases. Petición realizada igualmente por algunas familias que vivían en pueblos de la provincia, con la intención de que sus hijos pudieran volver a casa. La causa que motivaba esta petición era la carencia de refugio antiaéreo en el centro, además de su emplazamiento en un lugar estratégico, por lo que

\footnotetext{
${ }^{33}$ BO de 8 de septiembre de 1936, p. 72.

${ }^{34}$ Véase PALOMARES IBÁÑEZ, Jesus M., La guerra civil en la ciudad de Valladolid: entusiasmo y represión en la "capital del alzamiento", Valladolid, Ayuntamiento de Valladolid, 2001.

${ }^{35}$ De primera y segunda enseñanza. Memoria del colegio de Lourdes del curso 1938. AUVa, Legajo 2863.
} 
pudiera ser objetivo de la aviación ${ }^{36}$. Además, los desplazamientos de población provocados por la contienda - desde zonas no liberadas - causaron una masificación en las aulas, y el aumento del número de estudiantes en todos los centros educativos urbanos.

Fracasado el golpe de Estado, la guerra civil se presentó como una lucha «por Dios y por España» frente a los «sin Dios y sin Patria» ${ }^{37}$. Este sincretismo entre religión y política, a tono con una identificación Dios-patria, se convierte en pilar angular del denominado nacionalcatolicismo, que considera esencia de la nación a la milenaria religión católica ${ }^{38}$. El nacionalcatolicismo no es, sin embargo, una formulación teórica totalmente original del régimen franquista, sino que su proceso de elaboración se remonta, al menos, a las décadas finales del siglo XIX, enlazando con el integrismo católico y el carlismo, y constituyéndose paulatinamente como respuesta al crecimiento del movimiento obrero y al nacimiento de los nacionalismos periféricos como base ideológica del bloque social dominante. Alfonso Botti ha defendido que el nacionalcatolicismo no era un producto de la guerra civil y el franquismo, más bien lo contrario, entendiendo que el régimen franquista era una cristalización del nacionalcatolicismo, y que este servía además como explicación de las dinámicas del conflicto, unificando las fuerzas políticas y sociales concentradas en torno a Franco ${ }^{39}$. La guerra civil y la cruzada fueron presentadas como el cumplimiento del destino histórico y religioso del país, «como la inmolación de la patria enferma desde el siglo XIX. La santificación del recuerdo de la sangre derramada actuó durante la Dictadura como memoria palingenésica de la pasión, muerte y resurrección de la patria» ${ }^{40}$.

El papel protagonista de la educación pasó a la Iglesia, llegando a equivaler educación y cultura a religión. Los valores ideológicos del nuevo régimen son la antítesis de los valores educativos republicanos, recuperándose los valores tradicionales y ultraconservadores. La educación va a estar regida por los referentes de la religión, la moral y la familia difundidos e impuestos por el Movimiento ${ }^{41}$. En los primeros años tras la guerra asistimos a una lucha entre Falange y la Iglesia por dominar el ámbito educativo, lucha por el control de la formación y socialización de las futuras élites dirigentes del país. La derrota militar de los fascismos en la Segunda Guerra Mundial abría un nuevo período para el franquismo, perceptible ya en 1942. Va a ser ahora cuando el

\footnotetext{
${ }^{36}$ AHPV, Gobierno Civil, caja 356.

${ }^{37}$ MAZA, Elena, La idea de España en el Franquismo: el Nacionalcatolicismo, en MAZA, Elena (coord.), Homenaje al profesor Jesús María Palomares, Valladolid, Universidad de Valladolid, 2006, p. 604.

${ }^{38}$ MAZA, Elena, «El mito de Isabel de Castilla como elemento de legitimidad política en el franquismo», in Historia y política: Ideas, procesos y movimientos sociales, 31, 2014, pp. 167-192.

${ }^{39}$ BOTTI, Alfonso, Cielo y dinero: el nacionalcatolicismo en España (1881-1975), Madrid, Alianza, 1992, esp. pp. 124148.

${ }^{40}$ RINA, César, Los imaginarios franquistas y la religiosidad popular (1936-1949), Badajoz, Diputación de Badajoz, 2015, p. 31.

${ }^{41}$ CELADA, Pablo, ESTEBAN, Fernando, La política educativa en los primeros momentos del franquismo: depuración ideológica y educación tradicional, in RUIZ BERRIO, Julio (coord.), La educación en España a examen (1898-1988). Jornadas nacionales en conmemoración del centenario del noventayocho, Zaragoza, Ministerio de Educación y cultura. Institución Fernando el Católico, 1999, pp. 341.
} 
nacionalcatolicismo se convierta en eje de la política del franquismo, tanto en el interior como en el exterior, al menos hasta 1959 que irá cediendo terreno ${ }^{42}$.

Este espacio didáctico es un buen elemento para comparar el régimen franquista con el fascismo italiano, que en buena medida sirvió de modelo al régimen español, aunque también el sistema alemán. Como sostiene Morente Valero, al menos hasta 1943 la pedagogía y las políticas educativas de los regímenes fascistas europeos ejercieron una influencia más que notable sobre la enseñanza en España, compatible con una orientación católica de la misma y con una destacada presencia confesional entre el personal político encargado de llevarla a cabo. Hay una gran semejanza entre la política educativa del fascismo italiano y las reformas iniciadas por el franquismo durante la guerra e inmediata posguerra, incluida la Ley para la Reforma del Bachillerato de 1938. La reforma Gentile ${ }^{43}$ (1923-1924) - calificada como la «más fascista de las reformas» - introdujo la obligatoriedad de la enseñanza religiosa en las escuelas elementales del Estado. Posteriormente, entre 1925 y 1936, nuevas medidas modificaron la reforma Gentile, con la finalidad de transformar la escuela en un instrumento propagandístico, capaz de propalar a amplias capas de la sociedad los principios y las realizaciones del nuevo régimen, permitiendo una mayor difusión y afianzamiento del fascismo. Entre las medidas tomadas despuntan, por su semejanza, la exigencia a los docentes de prestar juramento de fidelidad al régimen, el cambio de nombre del Ministerio della Pubblica Instruzione, que pasa a llamarse de Educación Nacional o la depuración de los libros de texto de escuelas y bibliotecas. Concuerdan también el ambiente de exaltación patriótica en la vida escolar, la celebración recurrente de ritos y actos con la intención de fomentarlo, y el impulso a la educación física y la instrucción militar. Además ambos modelos de bachillerato propuestos por los dos regímenes son elitistas y clasistas, limitando el acceso de los estudiantes a la enseñanza superior, reservándola para las clases acomodadas y considerando el bachillerato como la antesala de la Universidad ${ }^{44}$.

El régimen franquista en ciernes consideraba que la reforma del bachillerato era «el instrumento más eficaz para, rápidamente, influir en la transformación de la sociedad y en la formación intelectual y moral de sus futuras clases directoras». Aunque es necesario señalar que la orientación clerical y conservadora de la reforma del bachillerato de 1938 provocó la oposición de algunos falangistas, como Dionisio Ridruejo y Antonio Tovar ${ }^{45}$. Dentro de las materias impartidas, la Historia de España es considerada «segunda religión de los españoles», en palabras

\footnotetext{
${ }^{42}$ DE PUELLES, Manuel, «Política y educación. Cien años de historia», in Revista de educación, núm. extra $1 / 2000$, pp. 7,36 , pp. 20-21.

${ }^{43}$ Véase AMBROSOLI, L., La scuola secondaria, in CIVES, Giacomo (a cura di), La scuola italiana dall'Unità ai nostro giorni, Scandicci-Firenze, La Nuova Italia, 1990, pp. 105-151.

${ }^{44}$ MORENTE, Francisco, «Los fascismos europeos y la política educativa del franquismo», in Historia de la educación, 24, 2005, pp. 179-204.

${ }^{45}$ FERNÁNDEZ SORIA, Juan Manuel, Estado y educación en la España contemporánea, Madrid, Síntesis, 2002, p. 137.
} 
de José Pemartín. En sus textos se reinterpreta la historia nacional en clave católica, guiada por la providencia. La historia en el bachillerato va a ser sin lugar a dudas una asignatura privilegiada, debido a su utilidad en la construcción de identidades ${ }^{46}$. Igualmente, podía crear una sociedad sumisa, carente de capacidad crítica, paralizada por el temor a la represalia. Cualquier atisbo de pensamiento liberal y renovador fue eliminado mediante unos eficaces medios represivos, siendo el proceso depurador del profesorado el más importante ${ }^{47}$. Para los sublevados, los enseñantes serían el origen y vía de difusión de la anti-España y de los elementos detonadores de la guerra civil. En palabras de Pemán eran «los envenenadores del alma popular [...] y han sembrado de duelo la mayoría de los hogares honrados de España»" ${ }^{48}$. El tratamiento dado a la enseñanza oficial y a la privada, favoreciendo esta última ${ }^{49}$, se revela en el marcado carácter religioso y patriótico del sistema educativo. También en las medidas de control ideológico ya citadas, como la depuración docente y la purga de textos. En origen, la intención era crear una nueva enseñanza para un nuevo Estado, como señala Manuel Utande ${ }^{50}$. Arranca por lo tanto una política educativa cuyo objetivo es recristianizar el país y restaurar la formación católica de la juventud, a través de una cultura política que doblegue a los vencidos consolidando el poder de los vencedores ${ }^{51}$.

A este predominio religioso y totalitarismo político se sumará el Frente de Juventudes, pretendiendo formar a sus afiliados para ser futuros miembros de Falange y adictos al Movimiento. La politización de la enseñanza y la intrusión de elementos falangistas en los colegios privados de Valladolid - en su mayor parte dirigidos por congregaciones religiosas- no fue bien recibida. Desde la guerra y hasta el año 1942 los partes mensuales de FET-JONS, remitidos a la Delegación Nacional de Provincias, aluden a las tensas relaciones con las instituciones privadas, llegando a dificultar la asistencia del alumnado a las actividades de la OJ. A partir del citado año, las relaciones son más fluidas pero aun así los colegios se muestran poco colaborativos. Con los años, los partes hablan de buenas relaciones, pero siempre manifestando la ausencia de entusiasmo por parte de las fundaciones docentes ${ }^{52}$. Además, las asignaturas implantadas por el Frente de Juventudes fueron encajadas en horarios residuales, sobre todo en los espacios

\footnotetext{
${ }^{46}$ MAZA, Elena, La idea de España, cit., p. 611.

${ }^{47}$ MARTÍN, Francisco, GRANA, Isabel, SANCHIDRIÁN, Carmen, «La depuración de los docentes: control y sometimiento ideológico del profesorado de instituto", in Historia de la Educación, 29, 2010, pp. 241-258.

${ }^{48}$ OTERO, Luis Enrique (dir.), La destrucción de la ciencia en España: depuración universitaria en el franquismo, Madrid, Universidad Complutense, 2006, p. 60.

${ }^{49}$ El Estado se atribuyó un papel subsidiario en materia educativa, sobre todo en lo referente a la segunda enseñanza.

${ }^{50}$ UTANDE, Manuel, «Treinta años de enseñanza media (1938-1968) », in Revista de Educación, 240, 1975, pp. 73-86.

51 MAYORDOMO, Alejando (coord.), Estudios sobre política educativa durante el franquismo, Valencia, Universidad de Valencia, 1999.

${ }^{52}$ GÓMEZ CUESTA, Cristina, Discurso y adoctrinamiento ciudadano en Valladolid durante el primer franquismo (1939-1959). Tesis doctoral en Historia, Universidad de Valladolid, 2007, pp. 183-185.
} 
dedicados al tiempo de ocio en estas instituciones, jueves por la tarde o sábados ${ }^{53}$. Por las memorias de los centros privados sabemos que su alumnado dedica estas horas a paseos vigilados por las calles de la localidad o actividades en los campos deportivos de los colegios, sin hacer referencia alguna a cursar esta asignatura.

Acabada la guerra, un nuevo calendario festivo será impuesto, con ritos acordes a la creación de un nuevo simbolismo (como ha señalado Giuliana di Febo, el Franquismo instituyó un ceremonial barroco), en el que un número elevado de fiestas rememoran directamente la guerra y los mártires de la Cruzada ${ }^{54}$ : Día de los Caídos, Fiesta del Caudillo, Día de la Victoria o Día de la Canción. Había que crear fiestas, gestos, normas y mitos nuevos para que se convirtieran en tradiciones. Mitos y cultos, que no se mantenían aislados, sino que se ponían en funcionamiento mediante el uso de símbolos: materializaciones visibles y concretas de los mitos en las que la gente podía participar (conformando a su vez una identidad del pueblo) y que «acabaron por proporcionar la esencia de la política fascista ${ }^{55}$. Asistimos a un proceso de nacionalización de las masas, que busca su homogeneización ideológica, mediante diversos mecanismos, entre ellos el uso de las fiestas y símbolos políticos, pretendiendo la sumisión de la sociedad al nuevo Estado para consolidar una imagen legitimadora de la Dictadura y la necesidad de un «salvador» de España y de Franco como «caudillo salvador» ${ }^{56}$.

El calendario de fiestas oficiales recogía tres tipos de fechas: las de carácter religioso, en consonancia con el espíritu católico que pretendía recuperarse; por esta vía se insistía en la legitimación de las instituciones políticas a través del uso de las formas de religiosidad, elementos propios de la «religiosidad política» ${ }^{57}$. Junto a las fiestas religiosas, aparecen las de carácter nacional y tradicional, como el Dos de Mayo -celebrado en todos los colegios con conferencias sobre diversos aspectos de la guerra de la Independencia-, la Fiesta de la Raza (12 de octubre); y las creadas en relación al Movimiento. Además la celebración del 18 de julio y del 1 de abril son exhibiciones evidentes de los signos externos de la victoria.

Como no podía ser de otra manera, los centros docentes también participarán de estas festividades. El Día de la Victoria los alumnos concurrirán a las celebraciones en el marco urbano, e incluso llegarán a organizar las suyas propias. Así el colegio de Lourdes dispondrá un desfile por

\footnotetext{
${ }^{53}$ MARÍN, José Ma , Historia Política, 1939-2000, Madrid, Itsmo, 2001, p. 126.

${ }^{54}$ Construyéndose a la vez la idea de que toda la sociedad tenía una deuda con ellos, no solo mártires también héroes, pues habían dado su sangre por la salvación de España

${ }^{55}$ MOSSE, George L., La nacionalización de las masas, Madrid, Marcial Pons, 2005, pp. 17-25.

${ }^{56}$ SEVILLANO, Francisco, «Cultura, propaganda y opinión en el primer franquismo», in Ayer, 33, 1999, pp. 147-166.

${ }^{57}$ BOX, Zira, «La tesis de la religión política y sus críticos: una aproximación al debate actual», in Ayer, 62, 2006, pp. 195-230. Véase también: ID., España, año cero. La construcción simbólica del franquismo, Madrid, Alianza Editorial, 2010.
} 
el patio portando banderas nacionales al son de cornetas y tambores ${ }^{58}$. En todos ellos tendrá una gran importancia la celebración del Nuestra Señora del Pilar, también denominada Fiesta de la Raza y Fiesta de la Hispanidad, siempre acompañada en las instituciones educativas de charlas que inciden en los diferentes aspectos de la celebración. Aunque esta efeméride estaba fuertemente arraigada en los centros religiosos, celebrándose desde hacía décadas, Zira Box señala que en los años treinta esta festividad se había ligado aun más al catolicismo y al concepto de raza. En los colegios la efeméride de la Hispanidad sirve para impartir charlas sobre la el Imperio español, así en el colegio de Lourdes en el curso $1942-1943^{59}$, tuvo lugar una conferencia sobre «La raza y la hispanidad», con la intención de rebatir la leyenda negra de España.

En este afán por sacralizar la política, el culto a los caídos se convirtió en uno de los distintivos principales del ritual franquista. Dicha práctica estaba ligada a la construcción monumental. Los colegios de San José y Lourdes, dedicados al alumnado masculino, levantaron monumentos a sus estudiantes fallecidos en la guerra civil, celebrando ambos centros el Día de los Caídos una misa y homenaje en sus respectivas construcciones conmemorativas ${ }^{60}$. Como esta efeméride se había instituido en torno al aniversario de la muerte de José Antonio Primo de Rivera, acompañaban dicha festividad con lecciones sobre la vida del líder falangista ${ }^{61}$, pero también con una misa por el eterno descanso de su alma. No olvidaban tampoco el aniversario de la fundación de Falange, acudiendo los alumnos encuadrados en el Frente de Juventudes al Teatro Calderón ${ }^{62}$.

Esta veneración a los muertos era a la vez un recuerdo a los vivos del modelo a seguir, de la valentía, fe y capacidad de sacrificio por la patria. Las revistas colegiales editadas durante la guerra y la posguerra recogen esta nueva mentalidad. Vemos artículos de alabanza a la labor de Onésimo Redondo, a Falange, a la purificación que supone la guerra, junto a relatos sobre la vida de los «caídos por Dios y por España», a modo de hagiografías. Así en el colegio del Lourdes, donde estudió el «caudillo de Castilla» la memoria escolar del curso 1936-1937 está dedicada a los egresados «caídos» en el frente; enalteciendo en diversos artículos la figura de Onésimo Redondo. De tal forma que el artículo «Vivan los muertos» calificaba a Redondo como «gloria de nuestro Colegio»; igualmente, la reseña «El Caudillo de nuestros héroes» recogía las virtudes de dicha figura ${ }^{63}$.

\footnotetext{
${ }^{58}$ Memoria del curso 1943-1944, ACNSL.

${ }^{59}$ Memoria del curso 1942-1943, ACNSL.

${ }^{60}$ Memoria del curso 1943-1944, ACNSL. Vallisoletana, 60/1943, Archivo Colegio de San José (ACSJV).

${ }^{61}$ En 1938 el MEN disponía que el 22 de noviembre debía impartirse en todos los centros de enseñanza de la zona sublevada una lección sobre la vida y obra de José Antonio. BOE, 19.11.1938.

${ }^{62}$ Vallisoletana, 65/1943, ACSJV. En este teatro tuvo lugar, el 4 de marzo de 1934, la unión de las Juntas de Ofensiva Nacionalsindicalista de Onésimo Redondo y Ramiro Ledesma Ramos con la Falange Española de José Antonio Primo de Rivera.

${ }^{63}$ Memoria escolar número 5. Curso de 1936-1937, ACNSL.
} 
Mientras la etapa republicana supuso un avance para la formación femenina, desde el golpe de Estado se llevo a cabo una identificación entre regeneración nacional, redención moral y recristianización, por lo que la identidad de género fue redefinida en clave nacionalcatólica, entremezclando hogar, religión y patria ${ }^{64}$. Así, se utilizará también el sistema educativo para reforzar la división de géneros, subordinado a las mujeres a los propios fines del sistema. De este modo, en la formación femenina se siguen pautas diferentes a la educación masculina ya que el fin último del Estado era convertirlas en «ángeles del hogar», apoyado este modelo por dos instituciones fundamentales en esta labor, la Sección Femenina y la Acción Católica femenina. Aunque en el caso concreto de Valladolid, en el estudio de colegio de La Enseñanza no han podido apreciarse cambios profundos de unos modelos educativos a otros, más allá de mostrar un sentimiento de rechazo a la República y un silencio ante las manifestaciones externas de la Dictadura.

\section{Conclusiones}

En nuestra investigación hemos analizado la educación secundaria en tres mo-mentos diferenciados: la Segunda República, la guerra civil y el franquismo, cada uno con sus rasgos sociopolíticos concretos, conformes a la legislación corres-pondiente y al empeño de cada gobierno por inculcar su propia ideología, ejer-ciendo un impacto social, cultural y político que trasciende en años posteriores. Ni la Segunda República ni la Dictadura escondieron la intención de infundir sus principios en la educación, presentando cada uno su modelo propio, identificando ambos regímenes sus propuestas con un nuevo espíritu educativo. La duración de estos arquetipos está bien diferenciada, teniéndose en cuenta además, que mientras el gobierno republicano comprendió cinco años, la dictadura franquista se extendió casi cuatro décadas. Por lo tanto, la incidencia en los centros educa-tivos tuvo un carácter desigual atendiendo al modelo y el tiempo. En la realidad vallisoletana, durante la Segunda República la mayor incidencia tendrá lugar en los institutos Zorrilla y Núñez de Arce. Otro fue el sesgo que observamos en los centros confesionales, según advierte la clausura del colegio de San José, pero la mayoría de las fundaciones religiosas siguieron funcionando sin apenas modifi-caciones. El modo de ejercer la educación no varió sustancialmente en la ense-ñanza confesional. En los colegios cuyo profesorado eran católicos seglares y religiosos sin hábito se difundían los principios de una emergente cultura de resistencia contra las premisas laicas, igualitarias y democratizadoras de la cultura republicana. $Y$ todo

\footnotetext{
${ }^{64}$ DI FEBO, Giuliana, La cuna, la cruz y la bandera. Primer franquismo y modelos de género, in MORANT DEUSA, Isabel, Historia de las mujeres en España y América Latina, Madrid, Cátedra, 2006, pp. 217-237.
} 
ello sin mermar la defensa de la religión, la monarquía o los privilegios sociales, llegando a generar una confrontación sociopolítica que des-borda el propio sistema.

Desde la guerra y durante las primeras décadas del franquismo - e incluso hasta los cambios de la Ley General de Educación (1970) - la nueva política educativa tendría un marcado carácter contrarreformador respecto de la República que, se estimaba, había supuesto una revolución. Retornando a la doctrina tradicional de la Iglesia fijada por la encíclica Divini Illius Magistri. La presencia abrumadora de la Iglesia en la educación, sobre todo en la enseñanza secundaria, y en total sintonía con los planteamientos educativos del régimen, derivó en una organiza-ción dentro de la rígida ortodoxia católica. En los años del franquismo, continúan su actividad mediante una identificación con el nuevo régimen, sujetos a su con-trol pero también en buena sintonía con los vencedores de la guerra. El nuevo modelo encajó a la perfección con las culturas escolares desarrolladas por los colegios religiosos, que durante la guerra e inmediata posguerra manifestaron con entusiasmo su adhesión a la Dictadura. Con el tiempo, este entusiasmo se fue atenuando. Aun así, el franquismo uniformizará los centros docentes, al igual que otras instituciones sometidas a su control, y además el Estado se decantó por la enseñanza privada - es necesario tener en cuenta que se defendía el prin-cipio de subsidiaridad en materia educativa -, debiendo esperar hasta 1964 para ver importantes inversiones estatales en educación. 


\section{EL AUTOR}

Sofia RODRÍGUEZ SERRADOR es Doctora en Historia por la Universidad de Valladolid. Ha cursado los estudios de Máster en Europa y el Mundo Atlántico: Poder, Cultura y Sociedad (Instituto Uni-versitario de Historia Simancas), y Máster Universitario de Profesor en Educación Secunda-ria Obligatoria y Bachillerato, Formación Profesional y Enseñanza de Idiomas. En los últimos años ha realizado estancias de investigación en Europa (École des Hautes Études en Sciences Sociales de París). Es coautora, junto al profesor Jesús Mª Palomares Ibáñez, del libro El Colegio Mayor Femenino "María de Molina" (1931-1975). Por una educación Universitaria Integral. Asimismo, ha participado en numerosos congresos nacional e internacionales.

URL: < http://www.studistorici.com/progett/autori/\#Rodríguez-Serrador> 